\title{
Temporal aspects of polar bear occurrences at field camps in Wapusk National Park, Canada
}

Michel P. Laforge ${ }^{a,}{ }^{,}$, Douglas A. Clark ${ }^{b}$, Aimee L. Schmidt ${ }^{b}$, Jessica L. Lankshear ${ }^{b}$, Sheldon Kowalchuk ${ }^{c}$, Ryan K. Brook ${ }^{d}$

${ }^{a}$ Department of Animal and Poultry Science, College of Agriculture and Bioresources, University of Saskatchewan, Saskatoon SK, S7N 5A8 Canada. Michel.laforge@usask.ca.

Current address: Department of Biology, Memorial University, 232 Elizabeth Avenue, St. John's NL, A1B 3X9.

${ }^{\mathrm{b}}$ School of Environment and Sustainability, University of Saskatchewan,

Saskatoon SK, S7N 5C8 Canada. Clark: d.clark@usask.ca; Schmidt: aimeelschmidt@gmail.com; Lankshear:

jessinthenorth@gmail.com

${ }^{c}$ Wapusk National Park and Manitoba North National Historic Sites, Parks Canada Agency, Churchill, MB ROB OEO, Canada. Sheldon.Kowalchuk@gov.mb.ca

${ }^{\mathrm{d}}$ Department of Animal and Poultry Science \& Indigenous Land Management Institute, College of Agriculture and Bioresources, University of Saskatchewan,

Saskatoon SK, S7N 5A8 Canada. ryan.brook@usask.ca

* Corresponding author current address: Michel P. Laforge, Department of Biology, Memorial University, 232 Elizabeth Avenue, St. John's NL, A1B 3X9. Phone: (306) 281-6425. m.laforge@mun.ca

\begin{abstract}
Interaction between polar bears (Ursus maritimus) and people is a growing concern for both bear conservation and human safety in a warming Arctic climate. Consequently, the importance of monitoring temporal trends in the proximity of polar bears to people has become critical in managing human-polar bear conflicts. Such concerns are acute in Wapusk National Park in Manitoba, Canada on the Western Hudson Bay coast, where we deployed 18 camera traps at three remote field camps from 2010-2014 ( 22,100 camera-days) to monitor the frequency and timing of bears' visits to those facilities. Following seasonal breakup of Hudson Bay's sea ice polar bear occurrences at these camps increased throughout the summer and into fall (low in May-July and increasing sharply through August-November and then approaching zero in December when Hudson Bay freezes). We quantified age and sex class and estimated body condition of bears visiting the camps: adult males were most prevalent at Nester One camp close to where adult males congregate at Cape Churchill, whereas the two camps farther south were visited more frequently by females with dependent young, likely traveling to and from a known maternal denning area. Few subadults were observed. As expected, body condition scores declined throughout the on-shore season. Our method of monitoring polar bear occurrence on shore is robust, cost-effective, and non-invasive, and so may provide an economical complement to data gathered through more conventional techniques.
\end{abstract}

Keywords: Climate change, Hudson Bay, human-wildlife conflict, non-invasive, polar bears, Ursus maritimus, Wapusk National Park 
Cite this article as: Laforge, M.P., Clark, D.A., Schmidt, A.L. et al. Polar Biol (2017) 40: 1661. The final publication is available at https://link.springer.com/article/10.1007/s00300-017-2091-6

\section{Introduction}

Current scientific knowledge of the causes and dynamics of conflicts between people and polar bears is insufficient for managing such conflicts; a problem that has become increasingly urgent as changes in the Arctic climate accelerate (Osvyanikov 1996; Clark 2003; Clark et al. 2012; Boisen 2014). Polar bears (Ursus maritimus) depend on sea ice in order to catch seals, which constitute the majority of their total annual diet. Where sea ice melts entirely in the summer, bears move onto shore and feed only opportunistically (Ramsay and Hobson 1991). As such, polar bears are particularly vulnerable to further reductions in the total number of days in which sea ice is present, which ultimately affects reproductive success, survival, and long-term population sustainability (Stirling et al. 1999; Derocher et al. 2004). Climate change driven alteration of sea ice dynamics have resulted in changes in polar bear habitat use (Ferguson et al. 2000; Pilfold et al. 2015). Earlier ice break-up has also been associated with increased mortality in juvenile, sub-adult and senescent polar bears (Regehr et al. 2007). Although it is well established that reduced sea ice is detrimental to polar bear populations (Stirling et al. 1999; Derocher et al. 2004; Amstrup et al. 2010; Hunter et al. 2010; Molnár et al. 2010; Rode et al. 2010; Molnár et al. 2011; Castro de la Guardia et al. 2013; Whiteman et al. 2015), knowledge about the specific nature and extent of effects from reduced access to sea ice on polar bears remains incomplete (Molnár et al. 2010; Molnár et al. 2011), and even where ice persists predation rates may decrease under changing environmental conditions (Pilfold et al. 2015). How the frequency, timing, spatial distribution, or outcomes of bear-human conflicts are affected by nutritional stress on polar bears resulting from changing and decreasing sea ice is still only known in generalities and this is a critical knowledge gap with far-reaching implications (Derocher et al. 2013).

Sea ice extent, structure, and thickness in the Canadian Arctic and sub-Arctic have seen dramatic changes in recent decades, with climate change causing a drastic reduction in the duration of ice coverage, especially along the southern edges (Perovich and Richter-Menge 2009). Changing ice phenology has the potential to increase the frequency of polar bear-human interactions, as nutritionally stressed bears may be more inclined to seek out anthropogenic sources of food (Stirling and Derocher 2012). Wapusk National Park, Manitoba, Canada contains two established (circa 1960s) and two new fields camps used by Parks Canada staff and researchers, and park staff raised concerns that the newly established camps may be serving as an attractant to polar bears. The park lies along the Hudson Bay coast: the bay is historically and currently ice-free in the summer (mid-August-late October), and current climate changeinduced trends display a lengthened ice-free period caused by earlier break-up and later freezeup (Gagnon and Gough 2005). Here and elsewhere in the Arctic, polar bear-human conflicts are much more frequent in the absence of sea ice (Gjertz and Persen 1987; Fleck and Herrero 1988; Stenhouse et al. 1988; Gjertz et al. 1993; Gjertz and Schie 1998; Dyck 2006; Boisen 2014). Consequently, present and future park management decisions demand detailed knowledge of what may increase or decrease the likelihood of such conflicts. To quantify the potential for human-bear interaction at these camps, which are the park's primary infrastructure, we installed a series of remotely-activated trail cameras to monitor bears visiting these camps. With that data we tested a series of preliminary hypotheses about factors that might be attracting or repelling bears from remote field camps in this seasonally ice-free region. 
Cite this article as: Laforge, M.P., Clark, D.A., Schmidt, A.L. et al. Polar Biol (2017) 40: 1661. The final publication is available at https://link.springer.com/article/10.1007/s00300-017-2091-6

Trail cameras have become an increasingly common tool for ecologists (Rowcliffe and Carbone 2008). Camera trapping has been used to monitor biodiversity (Ahumada et al. 2013; Gessner et al. 2014), estimate population density (Carbone et al. 2001; Rovero and Marshall 2009) and quantify activity patterns (Bridges et al. 2004; Campbell et al. 2006; Suselbeek et al. 2014; Stolle et al. 2015). This paper characterizes the temporal patterns of polar bear occurrences at field camps along the Hudson Bay coast in Wapusk National Park, in the context of current knowledge about the polar bear-sea ice relationship in western Hudson Bay. We also examine body condition and the temporal patterns among polar bear cohorts from our nonrandom study sites. To be clear, this study was not intended to sample or draw conclusions about the western Hudson Bay polar bear population. Our goal is very site- and contextspecific: to understand the patterns and nature of polar bear activity at these specific field camps, and to identify potential factors influencing that distribution, for further investigation. We consider what our findings to date mean for managing human-polar bear interactions and what they suggest will be needed to improve scientific understanding of the potential drivers of such interactions. Relating trends in these observations to changes in Arctic sea ice timing and duration could provide valuable insight for managing a vulnerable species in a changing Arctic environment. Based on our experience with this study we evaluate the feasibility of using trail camera data more broadly to non-invasively monitor polar bear activity and distribution on land in relation to annual sea-ice dynamics, and evaluate the feasibility of using these data as a tool in polar bear conservation efforts.

\section{Materials and Methods}

Study site

We collected data at three remote field camps in Wapusk National Park, Manitoba, Canada, distributed along the west coast of Hudson Bay (Fig. 1), several km inland (Nester One $=2.3 \mathrm{~km}$, Broad River $=4 \mathrm{~km}, \mathrm{Owl}$ River $=6 \mathrm{~km}$ ). During the summer and early autumn, our study area is frequented by a large proportion of the Western Hudson Bay population of polar bears which come ashore during the months when Hudson Bay is ice free (Stirling et al. 1977; Derocher and Stirling 1990; Stirling et al. 2004; Stapleton et al. 2014a). Population dynamics and habitat use of this population has been extensively studied (e.g., Derocher and Stirling 1995; Lunn et al. 1997; Regehr et al. 2007; Cherry et al. 2013), yet virtually nothing is known about polar bearhuman interactions outside communities in this region. In late summer and autumn, bears (primarily adult males) congregate at Cape Churchill in the north-eastern corner of the Park (Latour 1981). Nester One is much closer to Cape Churchill $(14 \mathrm{~km})$ than Broad $(75 \mathrm{~km})$ and Owl River (110 km). The documented distribution of polar bears in our study area during the ice-free period is largely associated with the Hudson Bay coastline, with the exception of females that travel considerable distances inland to a maternal denning area (Stirling et al. 1977; Derocher and Stirling 1990; Clark and Stirling 1998; Towns et al. 2010). Males tend to be found closer to the coast than females (mean $=5 \mathrm{~km}$ and $8 \mathrm{~km}$ for September and October, respectively, for males; $21 \mathrm{~km}$ and $42 \mathrm{~km}$ for females; Derocher and Stirling 1990; Clark and Stirling 1998).

These field camps are used intermittently throughout the year by park personnel, researchers, and field courses. Usage numbers are lacking but Nester One receives the highest level of visitation, with two, week-long field courses each August (maximum 16 people). 
Cite this article as: Laforge, M.P., Clark, D.A., Schmidt, A.L. et al. Polar Biol (2017) 40: 1661. The final publication is available at https://link.springer.com/article/10.1007/s00300-017-2091-6

Currently, Broad and Owl River camps are used primarily by small groups of park staff in late winter, spring, and early summer. Camps are accessed by helicopter in the summer and by snowmobile in the winter and spring.

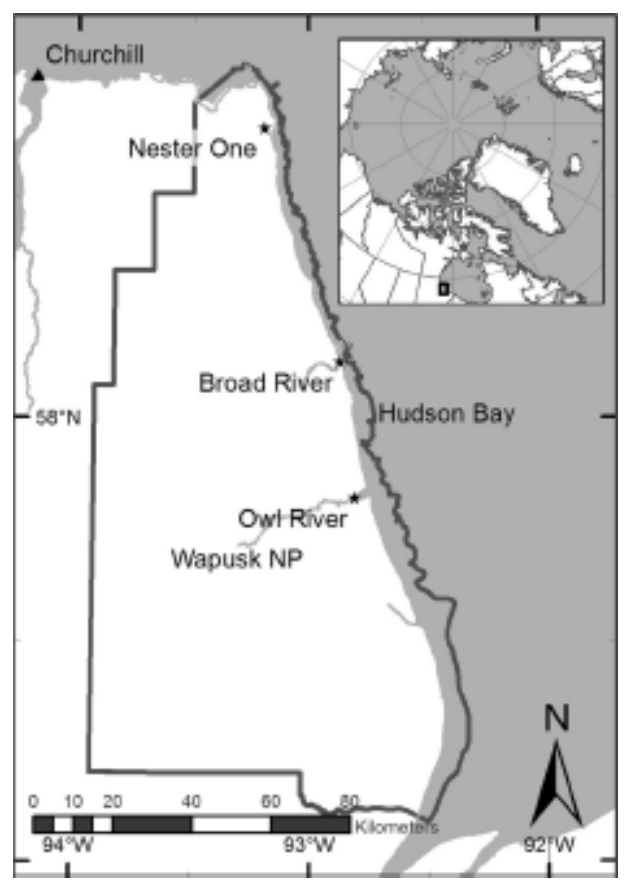

Fig. 1 Wapusk National Park, MB showing locations of the three field camps

Trail cameras

We deployed Moultrie (C) (2010 only) and Reconyx (C) PC-900 trail cameras (2011-present) at the three camps, with six cameras per year on average (range four to eight) at each site, with at least one camera placed in each cardinal direction. Each camera was protected by a Reconyx Heavy-Duty Security Enclosure, fastened with tamper-proof bolts (to avoid tooth damage to curious bears from padlock hasps), and attached $85 \mathrm{~cm}$ above ground to the camps' fenceposts using lag bolts, facing outwards. In 2010, Moultrie cameras were mounted on $5 \mathrm{~cm} \times 10 \mathrm{~cm}$ wooden boards just inside the fence wire. Cameras were left on default settings (high detectability, high-resolution images) and recorded three images, one second apart, at each activation (followed by a 10 second delay). All cameras had a 'covert' infrared flash, which is invisible to animals to avoid affecting the behaviour of animals photographed when the flash is triggered at night (Gibeau and McTavish 2009). Memory cards and batteries were replaced and images collected once per year in late June-early July of each year.

Data preparation and analysis

We quantified the number and time of visits by polar bears to each of the three camps. We defined an individual camp visit as any time any camera at a camp took a picture (presence) of at least one bear or family group (mother with dependent young). Subsequent presences of bears detected by any camera at the same camp within an hour of the previous presence were 
Cite this article as: Laforge, M.P., Clark, D.A., Schmidt, A.L. et al. Polar Biol (2017) 40: 1661. The final publication is available at https://link.springer.com/article/10.1007/s00300-017-2091-6

considered to be the same visit, unless we could clearly ascertain the presence of multiple individually-distinguishable bears present at camps at the same time; which only occurred once, with two family groups. Although the resolution and nature of the photographs precluded identifying each individual bear, in nearly all cases we were able to confirm with confidence that photos of bears taken within our 1-hour moving window were the same bear/family group. Each polar bear detection outside of the one-hour window was considered a unique detection whether it was by the same polar bear that returned later, or as was more often the case, a different bear visiting camps. This 1-hour moving window performed well, as we often had single visits where bears went undetected for $>0.5 \mathrm{hrs}$, but after this 1-hour cutoff, almost all subsequent photos of bears could reliably be considered a new visit (either a different bear/group, or the same bear returning at least 12 hours later). All statistical analyses were performed using R version 2.14.1 (R Development Core Team 2014).

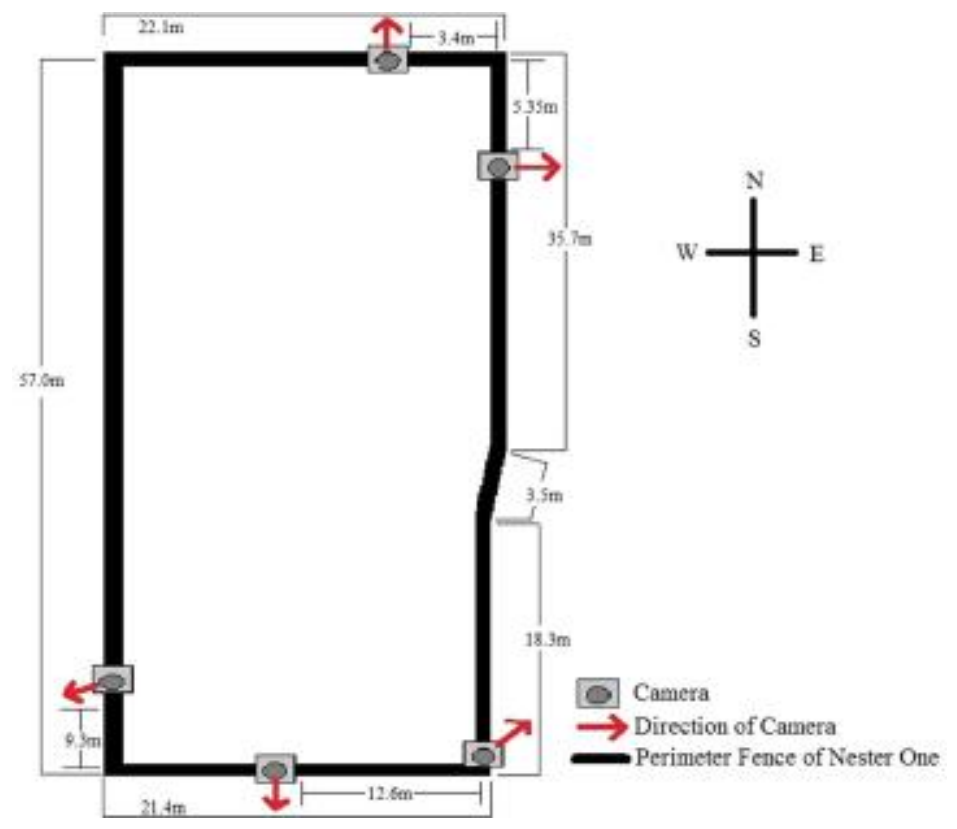

Fig. 2 Diagram of Nester One field camp in Wapusk National Park, MB, showing camp perimeter as well as location and direction of motion-acti-vated camera traps

Diurnal and Seasonal Distribution of Visits

We performed a Kuiper's one-sample test of uniformity on the circle (R package 'circular', Agostinelli and Lund 2013) to test whether bear visits were evenly distributed throughout the day.

We used data from Cherry et al. (2013) to determine the mean date that polar bears in the Western Hudson Bay population were expected to arrive on shore in the summer and depart on sea ice in the autumn as a function of sea ice extent (Canadian Ice Service 2013) in different years. Cherry et al. (2013) found that polar bears arrived ashore a mean of 28.3 days $($ S.E. $=1.8$ ) after the ice coverage of Hudson Bay had shrunk to $30 \%$ and returned to the sea ice an average of 2.5 days (S.E. $=0.7$ ) after $10 \%$ of the surface of Hudson Bay was covered in ice. 
Cite this article as: Laforge, M.P., Clark, D.A., Schmidt, A.L. et al. Polar Biol (2017) 40: 1661. The final publication is available at https://link.springer.com/article/10.1007/s00300-017-2091-6

Using these formulae and data from the Canadian Ice Service (2013) we calculated the expected date range that polar bears should be ashore for each year of our study (2010-2014; hereafter "on-shore season"). Based on these models, the mean expected date of arrival of bears on shore during the study period was August $4^{\text {th }}$ (range: Jul. $5^{\text {th }}-$ Aug. $12^{\text {th }}$ ) and the mean expected date of departure onto sea ice was November $24^{\text {th }}$ (range: Nov. $20^{\text {th }}-29^{\text {th }}$ ) across all four years.

We converted the date of polar bear visits to camps that were detected by our camera traps to a relative proportion of the on-shore season for that year (where $0=$ the mean date that bears were expected to arrive ashore that year based on ice conditions and $1=$ the mean date for their return to the sea ice). We generated a histogram of these relative dates of polar bear occurrence at remote camps during the period in which polar bears were expected to be on land. A chi-squared test was used to determine if polar bear visits were non-randomly distributed throughout the year (separated by month) as well as throughout the on-shore season, separated into five bins. We performed a linear regression to determine if mean body condition significantly declined throughout the ice free period when bears are on land, as well as across years as a function of the length of the on-shore season. We then calculated the probability of bears visiting each of the three camps for each month by dividing the total number of bear visits that occurred at the camp in a given month (pooled across years), by the number of active camera-days during that calendar month for the duration of the study.

\section{Characteristics of Bears Visiting Camps}

We estimated bear body condition from images using the standardized, visually-assessed body condition index ranging from 1 (very skinny) to 5 (very fat) as defined by Stirling et al. (2008). For mothers with cubs, we only assessed the body condition of the mother and for all bears we only assigned a score if we could see at least the entire torso in lateral view, or the full hindquarters and flank. When possible, we recorded the age and sex class of the individual(s) that visited the camps (lone males, lone females, sub-adults, females with cubs of year [assumed to have been born January $1^{\text {st }}$ and less than one year of age, Stirling et al. 1999], females with older cubs). Body condition and age and sex-class assignments were made by consensus between the two authors having multiple years of field experience with polar bears (DAC and RKB). This approach follows standard practice for visually assessing body condition in the field, yielding measures that- while coarse- are comparable across different regions and studies, and relatively insensitive to classification error (Stirling et al. 2008). Age-sex class determination was based on visual criteria including: presence of dependent young, visible penile hair or tail-area urine staining, head length/width ratio, observations of nipples, muzzle scarring, and whether body mass was carried primarily in the hindquarters (female) or more evenly distributed anterior-posterior (male). Apparent animal size in the camera frame was not used as a criterion because we could not reliably determine the bears' distance from cameras. Due to small sample sizes of polar bears detected at the Owl River camp, we combined data from Owl River and Broad River camps when analyzing demographic data. We used a chisquared test to test whether there was a difference in the distribution of age/sex classes visiting the Nester One versus the two river camps. 
Cite this article as: Laforge, M.P., Clark, D.A., Schmidt, A.L. et al. Polar Biol (2017) 40: 1661. The final publication is available at https://link.springer.com/article/10.1007/s00300-017-2091-6

\section{Results}

We recorded a total of 247 polar bear visits across the three research camps from July 2010June 2014. Overall, this represents a mean of 62 visits per year, representing about $6 \%$ of the total population of the Western Hudson Bay population ( 1030 bears), as estimated by Stapleton et al (2014a). Most (74.9\%) of polar bear visits to camps were recorded on more than one camera (mean $=2.85$ cameras /individual polar bear visit to a camp, $\mathrm{SE}=0.10$ ). Polar bear visits were not equally distributed across the three camps $(F=19.7, P=0.002, d f=2)$. Polar bears were detected with the highest frequency at Nester One $(143,57.9 \%)$ in all years, followed by Broad River (87, 35.2\%), and Owl River (17, 6.9\%).

Diurnal and Seasonal Distribution of Visits We found that bear visitation time was non-randomly distributed throughout the day (Kuiper's test: $3.32, p<0.01)$. Bears visited camps less frequently at night and more frequently during the day. Polar bear visits to camps were non-randomly distributed through the year $\left(X^{2}=439.8, p<\right.$ $0.001)$, and throughout the on-shore season $\left(X^{2}=73.2, p<0.001\right)$.

Polar bears visited the camps predominantly (77.3\% of all detections) during the onshore season as identified using Cherry et al.'s (2013) data, i.e. from mean dates of Aug. $4^{\text {th }}$ Nov $25^{\text {th }}$. The number of bear detections increased throughout the on-shore season, and peaked in the first week of November, before the mean date that bears returned to the sea ice (Fig. 2). The number of visits declined sharply after freeze-up and approached zero 16 days after $10 \%$ freeze up. Daily probabilities reflect a similar pattern, with the probability of encountering a bear increasing over the course of the on-shore season and peaking in November before declining in December (Fig. 3).

\section{Characteristics of Bears Visiting Camps}

Of 247 bear visits to camps, we were able to quantify bear body condition score for 204 bears (83\%). We only had partial photographs of bears in the remaining $17 \%$ of bear visits. The percentages of bears classified at each body condition score from $1-5$ were $0.5 \%, 17.2 \%, 65.7 \%$, $15.7 \%$ and $1.0 \%$ respectively. Mean body condition decreased throughout the year $(\beta=-$ $0.0033, \mathrm{SE}=0.00080$ body condition index score/day, $\mathrm{p}<0.001)$. We did not detect a difference in body condition as a function of the length of the on-shore season from 2011-2014 ( $p=0.23$ ). We did not have sufficient data to include body condition scores for 2010 . We were able to ascertain the age/sex class of 207 bears, and detected a total of 23 lone females, 32 females with cubs of year, 26 females with older cubs, 93 lone males, and 33 sub-adults. We were unable to confidently identify the age/sex class of 40 (16.2\%) of the bears photographed, because photos contained only part of a bear. We detected differences in the dominant age/sex class as a function of camp $\left(X^{2}=15.2, p=0.0042 ;\right.$ Fig. 3). Bear visitation at Nester One was dominated by lone adult males, whereas visitation at the more southern river campsfarther from optimal summer polar bear habitat and closer to the maternal denning area-was dominated by females with cubs of year. 
Cite this article as: Laforge, M.P., Clark, D.A., Schmidt, A.L. et al. Polar Biol (2017) 40: 1661. The final publication is available at https://link.springer.com/article/10.1007/s00300-017-2091-6

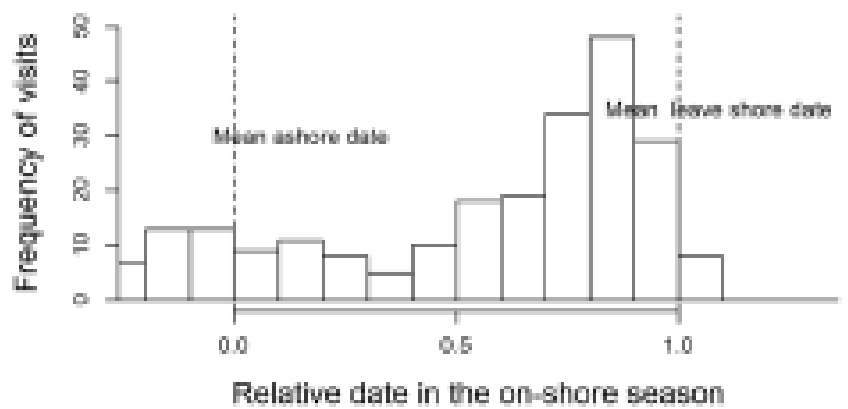

Fig. 3 Relative date of polar bear (Ursus maritimus) visitation ( $n=247 ; 2010-2014$ ) to camps in Wapusk National Park, Manitoba throughout the season in which bears are ashore. Dates were calcu-lated using data presented by Cherry et al. (2013) and data from the Canadian Ice Service (2013), with 0 representing the mean date in which polar bears were expected to come ashore and 1 representing the mean date in which they were expected to return to the ice (see "Methods" for full calculation)

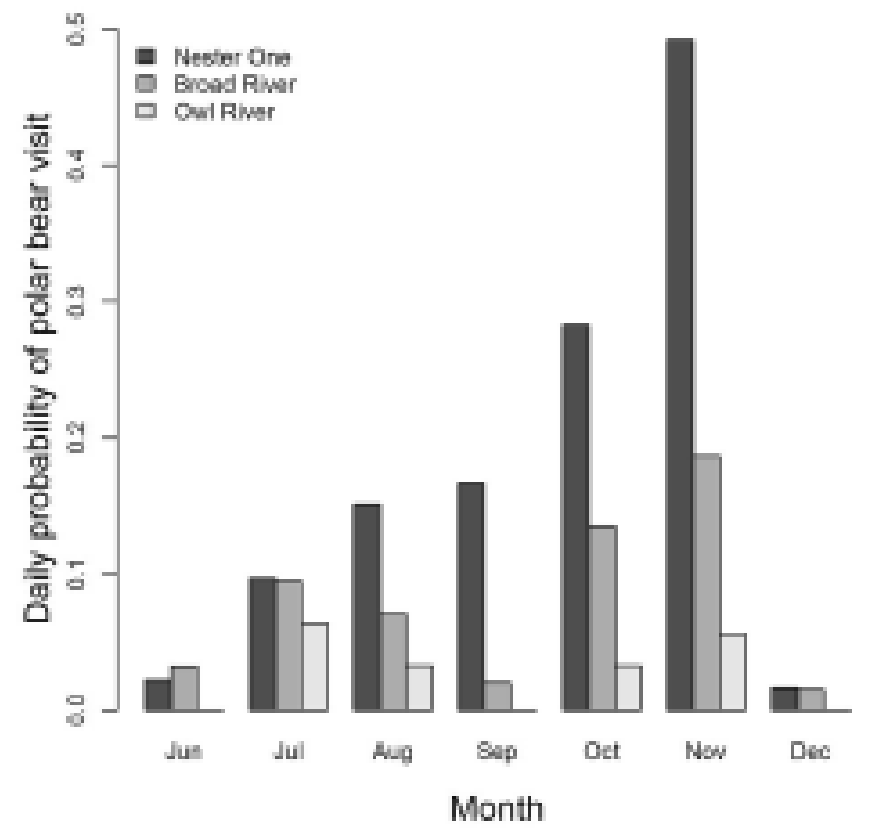

Fig. 4 Daily probability of detecting a polar bear (Ursus maritimus) as a function of month for three field camps in Wapusk, NP, 2010-2014 
Cite this article as: Laforge, M.P., Clark, D.A., Schmidt, A.L. et al. Polar Biol (2017) 40: 1661. The final publication is available at https://link.springer.com/article/10.1007/s00300-017-2091-6

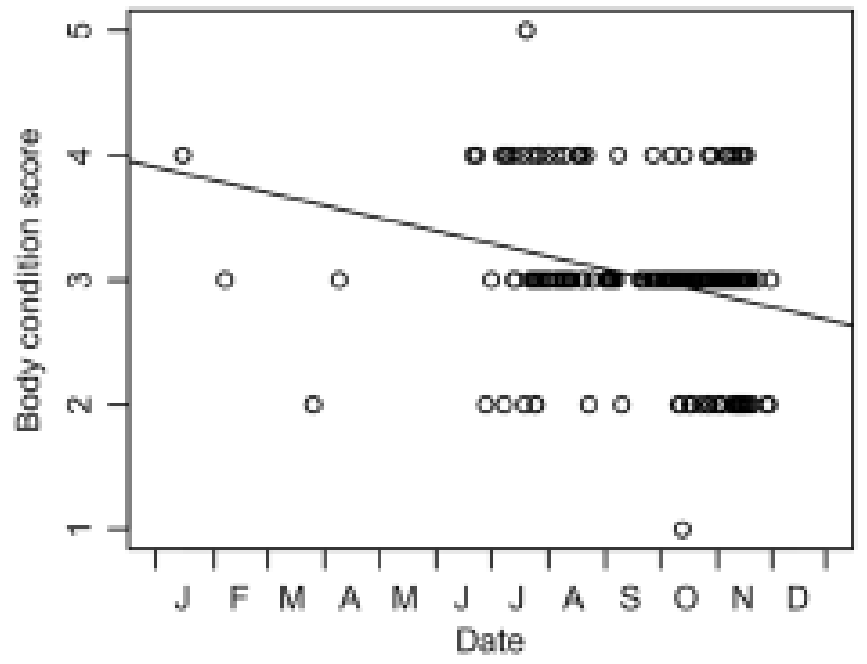

Fig. 5 Plot of polar bear (Ursus maritimus) body condition as a func-tion of day of year in Wapusk NP, 2010-2014

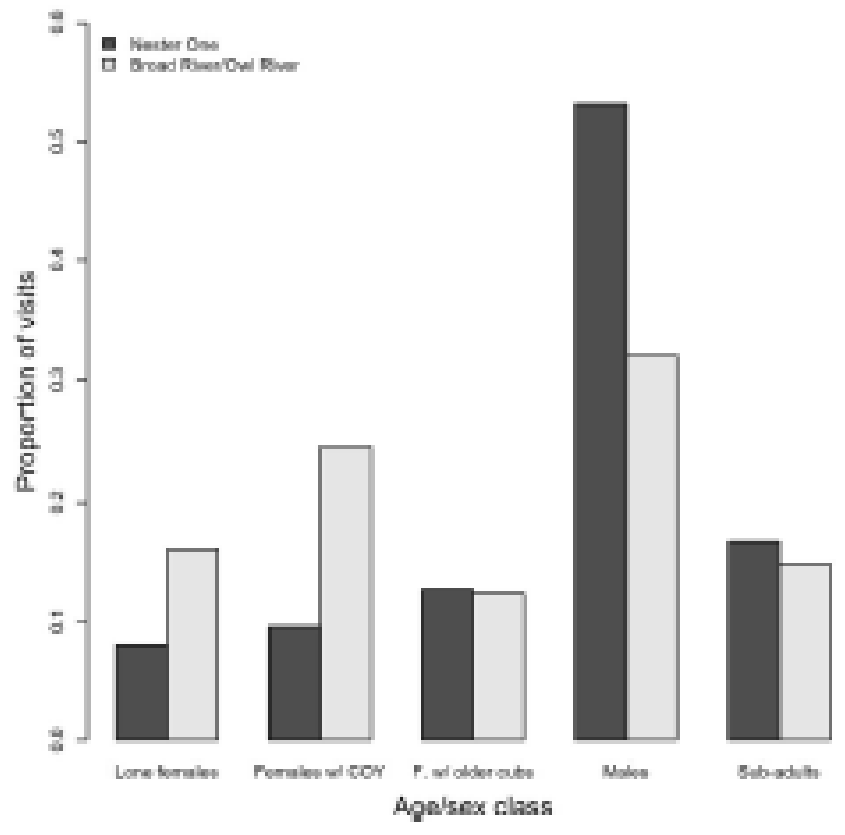

Fig. 6 Number of visits by polar bears (Ursus maritimus) by age and sex class as a function of field camp (Nester One versus Broad/Owl River) for polar bears in Wapusk NP, 2010-2014 
Cite this article as: Laforge, M.P., Clark, D.A., Schmidt, A.L. et al. Polar Biol (2017) 40: 1661. The final publication is available at https://link.springer.com/article/10.1007/s00300-017-2091-6

\section{Discussion}

Our finding that polar bears visited camps in Wapusk National Park almost exclusively during months when Hudson Bay was ice-free is consistent with previous published studies on polar bear distribution and activity patterns in the region (Stirling et al. 1977; Derocher and Stirling 1990; Clark and Stirling 1998; Cherry et al. 2013). Although that finding was unsurprising it is notable that these data, collected for the specific purpose of examining polar bear-human interactions at particular sites, are also able to detect the relative seasonal frequencies and timing of polar bears on shore in our study area with high precision.

Especially intriguing, and highly relevant for polar bear-human conflict management, was the temporal distribution of polar bear visits throughout the ice-free season, which increased over time, peaking in early November before declining sharply as bears left on newlyformed ice. Latour (1981) observed a similar abrupt increase in bears at Cape Churchill in November in the period before sea ice begins to establish. Derocher and Stirling (1990) also found that distance from the coast for all age and sex classes (except pregnant females in the denning area) dropped markedly and movement rate increased in November; however, movement rate was also high in August and distance to the coast was low in July. This would suggest a potential bi-modal distribution of visits, with a peak early in the season as bears come ashore as well as the peak we detected in late October/early November when bears move onto the new ice. As described by Clark and Stirling (1998) this likely reflects non-pregnant female bears moving purposefully to inland summer habitat early on in the ice-free season and later returning, versus remaining active around the coast anticipating freeze-up. Application of such findings to minimizing polar bear-human conflict is straightforward. For example, park managers can use the probabilities shown in Figure 2 to determine thresholds of acceptable risk of encounter and then schedule their field activities accordingly. Camps were generally occupied by people earlier in the ice-free season, when bear activity around camps was lower. It is possible that human camp use may affect the distribution of bear visits to camps, however given the timing of human camp use such an effect was not possible to disentangle from seasonal effects resulting from changing ice phenology entraining polar bear movement ecology.

It appears that the relatively small absolute distance inland from the coast to these camps isn't a deterrent to bears, but it is sufficient to influence the occurrence of different age and sex-classes. Experienced local land-users report that family groups use rivers to navigate from the denning area to the bay (D. Clark, unpublished data), and family groups returning to the bay in spring are known to follow a consistent northeasterly bearing that roughly parallels the main rivers (Ramsay and Andriashek 1986), therefore seeing a greater number of females with cubs at the more southerly camps situated along rivers was consistent with previous findings. Representation of age and sex-classes raise further questions. Females with cubs of year were seen with greater frequency than females with older cubs. This is likely largely due to cub mortality, which for the Western Hudson population ranges from 20-40\% (Stirling et al. 1999). Regehr et al (2007) suggested that declining environmental conditions could be associated with increased cub mortality and a shortened inter-birth interval for female polar bears in the Western Hudson Bay population. This would therefore result in an increased proportion of females with cubs-of-year. 
Cite this article as: Laforge, M.P., Clark, D.A., Schmidt, A.L. et al. Polar Biol (2017) 40: 1661. The final publication is available at https://link.springer.com/article/10.1007/s00300-017-2091-6

Given that sub-adults are consistently more often involved in human-polar bear encounters than other demographic classes (Clark et al. 2012), we had expected to see a greater proportion of visits from this group. This observation suggests that either subadults in this population have become warier of human infrastructure through some unknown mechanism, or they are simply low in this population due to unfavourable environmental conditions and low juvenile survival. Two recent independent field studies raised concerns about low juvenile survival in this population (Stapleton et al. 2014, Lunn et al. 2016) so we speculate the latter explanation is more likely, giving urgency to improving efforts to understand demographic changes in this population more accurately. However, we cannot rule out the possibility of behavioural or distributional changes in the younger generations of bears in this population that make them less likely to be observed by our cameras. In western Hudson Bay, monitoring the demographic structure of polar bear populations will clearly be crucial to documenting population-level responses to changing environmental conditions.

Our finding that polar bear body condition declined later in the on-shore season was consistent with the literature, as polar bears typically feed little and lose weight while on land. This trend has been noted by several other authors (Ramsay and Hobson 1991; Derocher et al. 1993; Atkinson and Ramsay 1995; Whiteman et al. 2015); however, the fact that we were able to detect this trend inexpensively and non-invasively by using camera traps is novel. As more data become available, we anticipate that using this method to monitor the condition of bears inter-annually, most notably in relation to sea-ice availability and the length of the on-shore season, could usefully inform polar bear conservation efforts in this region and elsewhere.

Camera-trapping has become widespread in wildlife research (Rowcliffe and Carbone 2008) and shows clear promise for studying aspects of polar bear ecology in a dynamic and remote environment. Traditional methods of studying polar bears such as telemetry-collaring provide invaluable insights into polar bear movement and habitat selection, however they have limitations. Collaring bears is expensive and time-consuming, limiting the number of animals that can potentially be collared. Capture and collaring has also been met with considerable concerns from northern communities due to both the perceived impacts on bears (McDonald et al. 1997), as well as a cultural perception of collaring being an inappropriate form of interaction with these animals (Tyrrell 2006; Stapleton et al. 2014a). As such, obtaining approval from northern communities for the use of collars in studying polar bears is not always assured. A changing Arctic environment could also pose challenges to current mark-recapture methods, as less sea ice could make capture more challenging and increase the risk of mortalities with bears being more stressed and having a lower body weight due to climate change (Derocher et al. 2004). This combination of influences has recently provided an impetus for researchers to explore new options for monitoring of polar bear populations (Stapleton et al. 2014a; Stapleton et al. 2014b). Prospectively, we expect such emerging methods to ultimately provide an important complement to telemetry-collar data.

One of the most attractive features of remote cameras over conventional monitoring methods such as collaring is their relative cost-effectiveness. Collaring bears is not an inexpensive procedure, costing upwards of $\$ 6,000 /$ animal for staff time and accommodations, helicopter, associated fuel costs, immobilization drugs, and collar purchase. Typically, several hundred animals must be handled during a robust mark-recapture study. Since 2011, our study 
Cite this article as: Laforge, M.P., Clark, D.A., Schmidt, A.L. et al. Polar Biol (2017) 40: 1661. The final publication is available at https://link.springer.com/article/10.1007/s00300-017-2091-6

used a total of 18 Reconyx trail cameras at a cost of $\$ 900$ USD each, plus memory cards (\$70 each), and batteries ( $\$ 55 /$ camera/year). Camera life expectancy under these field conditions is estimated at five to six years, and we have only had two camera failures to date in over 40 camera-years of year-round deployment. Overall, we have spent a total of $\sim \$ 42,000$ USD since 2011 , for an average operating cost of $\sim \$ 14,000$ USD per year, which includes camera costs, annual helicopter flights to collect data, batteries, and camera maintenance. Our project is also much less time-intensive; staff time is very limited as fieldwork can be done for the entire project in two days per year and the flights are often coordinated with other concurrent research projects to save costs. Once the cameras are deployed they only need to be visited once per year to retrieve images and change batteries. Although our cameras detected people using the field camps throughout the year, we did not have any issues with tampering with cameras.

Our method of observing polar bear occurrences, while promising, has limitations. There may have been a small proportion of bears that approached camp but were not detected by the cameras, since they did not cover the entire fenced perimeter. However, given the cameras' sensor geometry, bears would need to approach and leave camps from nearly the same angle to avoid detection. This is possible but unlikely to be frequent enough to affect our data. Images clearly show that most bears approaching camp come to within a few meters of the fence and then walk parallel to it, often investigating (and even chewing) the camera housings. Also, the bears observed were generally detected by more than one camera (mean $=2.85, \mathrm{SE}=$ 0.10). In the context of polar bears' known curiosity (Stirling 2011), this observed behaviour suggests that if our camera setup is biased, it is towards an increased likelihood of detecting of bears. Standardized criteria for age-sex class differentiation in polar bears should also be developed so that findings from studies such as this can be reliably compared with others in the future. Of particular relevance for managers, remote camera data are not accessible in realtime in remote regions and require manual collection; the potential advantage of real-time data for identifying and intervening in wildlife-human conflict situations is obvious. Camera placement and thus detection radius around camps is limited by having to mount cameras on the camp fences. Securely mounting cameras in a largely tree-less environment is difficult because polar bears regularly investigate field equipment and will quickly knock over infrastructure not cemented deeply into the ground, significantly limiting deployment options. The challenges in reliably identifying most individual animals limits the utility of camera data for conventional abundance and population dynamics studies, though advances in analytical techniques combined with increasing resolution of the cameras are promising (Rowcliffe et al. 2011).

Although we have been able to describe both temporal and spatial patterns of occurrences of polar bears at our study sites, along with some potentially relevant attributes of observed bears, important questions remain. Chief among these is exactly what factors influence those observed patterns. We have not yet collected sufficient data to determine whether human presence in the camps is an attractant or a deterrent and given current camp use levels amassing enough may take considerable time. Focused analysis of the behaviours exhibited by bears on camera would be interesting, but by itself hardly conclusive. Experimentally manipulating camp visitation, especially in autumn when these camps are 
Cite this article as: Laforge, M.P., Clark, D.A., Schmidt, A.L. et al. Polar Biol (2017) 40: 1661. The final publication is available at https://link.springer.com/article/10.1007/s00300-017-2091-6

typically empty, would be instructive and likely provide clearer answers than simply collecting more data with no deliberate changes to camp use routines. An alternative approach, and perhaps more pragmatic, would be to collect contemporaneous data from other camps in the region that are used in autumn, e.g. for polar bear viewing. Similarly, sea ice break-up and freeze-up dates varied little during our sampling period. An earlier break-up would likely put bears ashore in poorer condition on average, and this may influence their likelihood of investigating camps as potential anthropogenic food sources, especially in autumn. Given Lunn et al.'s (2016) findings about the varying sensitivity of different age and sex classes to diminished hunting opportunities, we recommend looking specifically for changes in the demographics among bears coming to camps. Such an effect could be investigated - and the relationship between ice dynamics, nutritional stress on bears, and likelihood of polar bearhuman conflicts better understood - by continuing this research over a number of years with varying ice conditions.

\section{Acknowledgements}

Financial and logistical support for this work was provided by Wapusk National Park, University of Manitoba, University of Saskatchewan, the Social Sciences and Humanities Research Council of Canada, Hudson Bay Helicopters, the Churchill Northern Studies Centre, and EarthRangers.

\section{Literature cited}

Agostinelli C, Lund U (2013) R package "circular": Circular Statistics. URL: https://r-forge.rproject.org/projects/circular/

Ahumada JA, Hurtado J, Lizcano D (2013) Monitoring the Status and Trends of Tropical Forest Terrestrial Vertebrate Communities from Camera Trap Data: A Tool for Conservation. PLoS One 8:e73707. doi: 10.1371/journal.pone.0073707

Amstrup SC, Deweaver ET, Douglas DC, Marcot BG, Durner GM, Bitz CM, Bailey DA (2010) Greenhouse gas mitigation can reduce sea-ice loss and increase polar bear persistence. Nature 468:955-958. doi: 10.1038/nature09653

Atkinson S, Ramsay M (1995) The effects of prolonged fasting of the body composition and reproductive success of female polar bears (Ursus maritimus). Funct Ecol 9:559-567. doi: $10.2307 / 2390145$

Boisen N. (2014) Safer people - Safer polar bears. World Wildlife Fund Norway, Oslo, Norway. URL: http://awsassets.wwf.no/downloads/wwf_a4_report_isbjornsrapport.pdf

Bridges A, Vaughan M, Klenzendorf S (2004) Seasonal variation in American black bear Ursus americanus activity patterns: quantification via remote photography. Wildlife Biol 10:277284.

Campbell TA, Langdon CA, Laseter BR, Ford WM, Edwards JW, Miller KV (2006) Movements of female white-tailed deer to bait sites in West Virginia, USA. Wildl Res 33:1-4. doi: 10.1071/WR04090

Canadian Ice Service (2013) IceGraph v2.0.6. URL: http://iceweb1.cis.ec.gc.ca/IceGraph20/page1.xhtml?lang=en. Accessed 10 Jun 2014 
Cite this article as: Laforge, M.P., Clark, D.A., Schmidt, A.L. et al. Polar Biol (2017) 40: 1661. The final publication is available at https://link.springer.com/article/10.1007/s00300-017-2091-6

Carbone C, Christie S, Conforti K, Coulson T, Franklin N, Ginsberg JR, Griffiths M, Holden J, Kawanishi K, Kinnaird M, Laidlaw R, Lynam A, Macdounal DW, Martyr D, McDougal C, Nath L, O'Brien T, Seidensticker J, Smith D, Sunquist M, Tilson R, Wan Shahruddin W (2001) The use of photographic rates to estimate densities of tigers and other cryptic mammals. Anim Conserv 4:75-79. doi: 10.1017/S1367943002002172

Castro de la Guardia L, Derocher AE, Myers PG, Terwisscha van Scheltinga AD, Lunn NJ (2013) Future sea ice conditions in Western Hudson Bay and consequences for polar bears in the 21st century. Glob Chang Biol 19:2675-2687. doi: 10.1111/gcb.12272

Cherry SG, Derocher AE, Thiemann GW, Lunn NJ (2013) Migration phenology and seasonal fidelity of an Arctic marine predator in relation to sea ice dynamics. J Anim Ecol 82:912921. doi: 10.1111/1365-2656.12050

Clark D (2003) Polar bear-human interactions in Canadian national parks, 1986-2000. Ursus 14:65-71.

Clark DA, Stirling I (1998) Habitat preferences of polar bears in the Hudson Bay lowlands during late summer and fall. Ursus 10:243-250.

Clark DA, van Beest FM, Brook RK (2012) Polar Bear-human conflicts: state of knowledge and research needs. Can Wildl Biol Manag 1:21-29.

Derocher AE, Aars J, Amstrup SC, Cutting A, Lunn NJ, Molnár PK, Obbard ME, Stirling I, Thiemann GW, Vongraven D, Wiig $\varnothing$, York G (2013) Rapid ecosystem change and polar bear conservation. Conserv Lett 6:368-375. doi: 10.1111/conl.12009

Derocher AE, Andriashek D, Stirling I (1993) Terrestrial foraging by Polar Bears during the icefree Period in Western Hudson Bay. Arctic 46:251-254.

Derocher AE, Lunn NJ, Stirling I (2004) Polar bears in a warming climate. Integr Comp Biol 44:163-176. doi: 10.1093/icb/44.2.163

Derocher AE, Stirling I (1990) Distribution of polar bears (Ursus maritimus) during the ice-free period in western Hudson Bay. Can J Zool 68:1395-1403. doi: 10.1139/z90-208

Derocher AE, Stirling I (1995) Estimation of Polar Bear Population Size and Survival in Western Hudson Bay. J Wildl Manage 59:215-221.

Ferguson SH, Taylor MK, Messier F (2000) Influence of sea ice dynamics on habitat selection by polar bears. Ecology 81:761-772. doi: 10.1890/0012-9658(2000)081[0761:IOSIDO]2.0.CO;2

Gagnon AS, Gough WA (2005) Trends in the dates of ice freeze-up and breakup over Hudson Bay, Canada. Arctic 58:370-382. doi: 10.1007/s10584-005-1815-8

Gessner J, Buchwald R, Wittemyer G (2014) Assessing species occurrence and species-specific use patterns of bais (forest clearings) in Central Africa with camera traps. Afr J Ecol 52:5968. doi: 10.1111/aje.12084

Gibeau M, McTavish C (2009) Not-So-Candid Cameras: How to prevent camera traps from skewing animal behavior. Wildl Prof 3:35-37.

Hunter CM, Caswell H, Runge MC, Regehr EV, Amstrup SC, Stirling I (2010) Climate change threatens polar bear populations: a stochastic demographic analysis. Ecology 91:28832897. doi: 10.1890/09-1641.1

Latour PB (1981) Spatial relationships and behavior of polar bears (Ursus maritimus Phipps) concentrated on land during the ice-free season of Hudson Bay. Can J Zool 59:1763-1774. 
Cite this article as: Laforge, M.P., Clark, D.A., Schmidt, A.L. et al. Polar Biol (2017) 40: 1661. The final publication is available at https://link.springer.com/article/10.1007/s00300-017-2091-6

Lunn N, Stirling I, Andriashek D, Kolenosky G (1997) Re-Estimating the Size of the Polar Bear Population in Western Hudson Bay. Arctic 50:234-240.

McDonald M, Arragutainaq L, Novalinga Z (1997) Voices from the Bay: Traditional ecological knowledge of Inuit and Cree in the Hudson Bay bioregion. Canadian Arctic Resources Committee, Environmental Committee of the Municipality of Sanikiluaq, Ottawa, ON and Sanikiluaq, NU

Molnár PK, Derocher AE, Klanjscek T, Lewis MA (2011) Predicting climate change impacts on polar bear litter size. Nat Commun 2:186. doi: 10.1038/ncomms1183

Molnár PK, Derocher AE, Thiemann GW, Lewis MA (2010) Predicting survival, reproduction and abundance of polar bears under climate change. Biol Conserv 143:1612-1622. doi: 10.1016/j.biocon.2010.04.004

Osvyanikov N (1996) Interactions of polar bears with other large mammals, including man. J Wildl Res 1: 254-259

Perovich DK, Richter-Menge JA (2009) Loss of sea ice in the Arctic. Ann Rev Mar Sci 1:417-441. doi: 10.1146/annurev.marine.010908.163805

Pilfold NW, Derocher AE, Stirling I, Richardson E (2015) Multi-temporal factors influence predation for polar bears in a changing climate. Oikos. doi: 10.1111/oik.02000

R Development Core Team (2014) R: A Language and Environment for Statistical Computing

Ramsay M, Andriashek D (1986) Long distance route orientation of female polar bears (Ursus maritimus) in spring. J Zool 208:63-72

Ramsay MA, Hobson KA (1991) Polar bears make little use of vterrestrial food webs: evidence from stable-carbon isotope analysis. Oecologia 86:598-600

Regehr EV, Lunn NJ, Amstrup SC, Stirling I (2007) Effects of earlier sea ice breakup on survival and population size of polar bears in Western Hudson Bay. J Wildl Manage 71:2673-2683. doi: $10.2193 / 2006-180$

Rode KD, Amstrup SC, Regehr EV (2010) Reduced body size and cub recruitment in polar bears associated with sea ice decline. Ecol Appl 20:768-782. doi: 10.1890/08-1036.1

Rovero F, Marshall AR (2009) Camera trapping photographic rate as an index of density in forest ungulates. J Appl Ecol 46:1011-1017. doi: 10.1111/j.1365-2664.2009.01705.x

Rowcliffe JM, Carbone C (2008) Surveys using camera traps: Are we looking to a brighter future? Anim Conserv 11:185-186. doi: 10.1111/j.1469-1795.2008.00180.x

Rowcliffe MJ, Carbone C, Jansen PA, Kays R, Kranstauber B (2011) Quantifying the sensitivity of camera traps: An adapted distance sampling approach. Methods Ecol Evol 2:464-476. doi: 10.1111/j.2041-210X.2011.00094.x

Stapleton S, Atkinson S, Hedman D, Garshelis D (2014a) Revisiting Western Hudson Bay: Using aerial surveys to update polar bear abundance in a sentinel population. Biol Conserv 170:38-47. doi: 10.1016/j.biocon.2013.12.040

Stapleton S, LaRue M, Lecomte N, Atkinson S, Garshelis D, Porter C, Atwood T (2014b) Polar bears from space: Assessing satellite imagery as a tool to track arctic wildlife. PLoS One 9:e101513. doi: 10.1371/journal.pone.0101513

Stirling I, Derocher AE (2012) Effects of climate warming on polar bears: A review of the evidence. Glob Chang Biol 18:2694-2706. doi: 10.1111/j.1365-2486.2012.02753.x 
Cite this article as: Laforge, M.P., Clark, D.A., Schmidt, A.L. et al. Polar Biol (2017) 40: 1661. The final publication is available at https://link.springer.com/article/10.1007/s00300-017-2091-6

Stirling I, Jonkel C, Smith P (1977) The ecology of the polar bear (Ursus maritimus) along the western coast of Hudson Bay. Canadian Wildlife Service

Stirling I, Lunn NJ, lacozza J (1999) Long-term trends in the population ecology of polar bears in western Hudson Bay in relation to climatic change. Arctic 52:294-306. doi: 10.14430/arctic935

Stirling I, Lunn NJ, lacozza J, Elliott C, Obbard M (2004) Polar bear distribution and abundance on the southwestern Hudson Bay coast during open water season, in relation to population trends and annual ice patterns. Arctic 57:15-26.

Stirling I, Thiemann GW, Richardson E (2008) Quantitative Support for a Subjective Fatness Index for Immobilized Polar Bears. J Wildl Manage 72:568-574.

Stolle K, van Beest F, Vander Wal E, Brook R (2015) Diurnal and Nocturnal Activity Patterns of Invasive Wild Boar (Sus scrofa) in Saskatchewan, Canada. Can Field-Naturalist 129:76-79.

Suselbeek L, Emsens W-J, Hirsch BT, Kays R, Rowcliffe JM, Zamora-Gutierrez V, Jansen PA (2014) Food acquisition and predator avoidance in a Neotropical rodent. Anim Behav 88:41-48. doi: 10.1016/j.anbehav.2013.11.012

Towns L, Derocher AE, Stirling I, Lunn N (2010) Changes in land distribution of polar bears in western Hudson Bay. Arctic 63: 206-212

Tyrrell M (2006) More bears, less bears: Inuit and scientific perceptions of polar bear populations on the west coast of Hudson Bay. Études/Inuit/Studies 30:191-208. doi: 10.7202/017571ar

Whiteman JP, Harlow HJ, Durner GM, Albeke SE, Regehr E V, Amstrup SC (2015) Summer declines in activity and body temperature offer polar bears limited energy savings. Science 349:295-298. 